\title{
Avaliação nutricional da silagem de grãos úmidos de sorgo de baixo ou de alto conteúdo de tanino para coelhos em crescimento
}

\author{
Antonio Claudio Furlan ${ }^{1}$, Cláudio Scapinello ${ }^{1}$, Ivan Moreira ${ }^{1}$, Elias Nunes Martins ${ }^{1}$ \\ ${ }^{1}$ Departamento de Zootecnia da Universidade Estadual de Maringá. Av. Colombo, 5790, CEP: 87020-900 - Maringá, PR.
}

\begin{abstract}
RESUMO - Dois experimentos foram realizados com os objetivos de determinar o valor nutritivo e verificar o desempenho de coelhos em crescimento alimentados com rações isoenergéticas contendo diferentes níveis de silagem de grãos úmidos de sorgo de baixo ou de alto conteúdo de tanino. No ensaio de digestibilidade (experimento 1), determinou-se o valor nutritivo de silagens de grãos úmidos de sorgo de baixo e alto conteúdo de tanino. Foram utilizados 30 coelhos (15 machos e 15 fêmeas) da raça Nova Zelândia Branco, com média de 55 dias de idade, distribuídos em um delineamento inteiramente casualizado, com três tratamentos e dez repetições. Em cada tratamento, as silagens de grãos avaliadas substituíram 30\% de uma ração-referência. Os teores de MS, MO, proteína, amido e energia digestíveis das silagens de grãos úmidos de sorgo de baixo e alto teores de tanino foram, respectivamente, 62,25 e $62,61 \%$; 91,99 e $89,05 \%$; 9,50 e 7,70\%; 66,22 e 65,76\%; e 4.285 e 4.116 kcal/kg na MS. No experimento de desempenho, foram avaliadas rações contendo níveis crescentes de silagem de grãos úmidos de sorgo de baixo e alto conteúdos de tanino $(0,33,66$ e 100\%) em substituição ao milho. Foram utilizados 84 coelhos da raça Nova Zelândia Branco (42 machos e 42 fêmeas) com idade inicial de 35 dias, distribuídos em um delineamento inteiramente casualizado, com sete tratamentos e 12 repetições, no qual a unidade experimental foi constituída de um animal. A análise de variância não comprovou diferenças entre os tratamentos para as características de desempenho, carcaça e custo por quilo de peso vivo ganho de coelhos em crescimento. Silagens de grãos úmidos de sorgo de baixo ou alto teores de tanino apresentam bom valor nutritivo e podem substituir totalmente o milho em rações para coelhos em crescimento.
\end{abstract}

Palavras-chave: carcaça, digestibilidade, valor energético

\section{Nutritional evaluation of high moisture sorghum silage grain with low or high tannin content for growing rabbits}

\begin{abstract}
Two experiments were carried out to determine the nutritive value and to evaluate the performance of growing rabbits fed on isoenergetic diets containing high moisture sorghum silage grain with low or high tannin levels. In the digestibility assay (experiment 1), the nutritive values of silages were determined with 30 New Zealand White rabbits, 15 males and 15 females, 55 days old, allotted in a completely randomized design, with 3 treatments and 10 replications. In each treatment the each sorghum silage replaced $30 \%$ basal diet. Values of digestible dry matter, organic matter, protein, starch and energy of high moisture sorghum silage grain with low or high tannin content were, respectively, on a dry matter basis, 62.25 and $62.61 \% ; 91.99$ and $89.05 \% ; 9.50$ and $7.70 \% ; 66.22$ and $65.76 \%$ and, 4,285 and $4,116 \mathrm{kcal} / \mathrm{kg}$. In performance trial diets containing increasing levels of high moisture sorghum silage grain with low or high tannin content $(0,33,66$ and $100 \%$ ) in replacement to corn were used. Eighty four New Zealand White rabbits (42 males and 42 females), 35 days old, were alloted in a completely randomized design, with 7 treatments and 12 replications each. There was no effect on performance, carcass and cost of ration per kilogram live weigh gain of growing rabbits. High moisture sorghum silage grain with low or high tannin content has good nutritive value and may totally replace corn in diets of growing rabbits.
\end{abstract}

Key Words: carcass, digestibility, energetic value

\section{Introdução}

O milho é um dos principais componentes das rações para animais monogástricos e seu custo tem sido um dos grandes problemas para os criadores. A crescente procura por esse cereal para uso na alimentação humana, aliada a produções limitadas em determinados anos, tem levado diversos produtores ao uso de ingredientes alternativos na alimentação animal. Nesse contexto, o sorgo granífero, por suas características nutricionais, tem sido avaliado como sucedâneo do milho (Rostagno, 1986).

O sorgo (Sorghum bicolor L. Moench.) é o quinto cereal mais plantado no mundo. À sua frente, encontram-se o trigo, o arroz, o milho e a cevada. A produção de sorgo na 
América do Norte, América do Sul, Europa e Austrália destina-se, principalmente, à alimentação animal, ao passo que, na Ásia, África, Rússia, China e América Central, o grão é utilizado na alimentação humana (Magalhães et al., 2000).

Enquanto nos Estados Unidos, maior produtor de sorgo, o rendimento é de 4,3 toneladas de grãos por hectare, no Brasil, a produção média é de 2,5 t/ha (Fontes, 2000).

De acordo com Nunes et al. (2001), o sorgo é um cereal com alta adaptabilidade aos diversos tipos de solos e climas encontrados no Brasil. Pode ser cultivado em áreas com menor disponibilidade de água e, por sua maior resistência hídrica, possibilita maiores opções de plantio que o milho. Em regiões semi-áridas e tropicais, a cultura do sorgo resulta em melhor rendimento de nutrientes por unidade de área (Rostagno, 1986).

O sorgo pode ser classificado como alimento energético, com nível de PB um pouco superior e níveis de aminoácidos essenciais ligeiramente inferiores ao do milho. Portanto, não se deve dar a importância ao nível mais elevado de PB do sorgo quando da formulação de ração (Rostagno et al., 2000).

O valor de EM está inversamente relacionado ao conteúdo de tanino do cereal, tornando impossível citar somente um valor energético para as diferentes variedades de sorgo (Rostagno, 1986).

Embora as análises químicas proximais dos dois grãos sejam semelhantes, o sorgo apresenta valor nutritivo de 90 a $95 \%$ do valor do milho quando utilizado em rações para suínos em crescimento e terminação (Gontijo et al., 1976).

O sorgo e o milho podem ser considerados equivalentes quanto aos teores de minerais e vitaminas. Contudo, o sorgo é deficiente em EE e substâncias pigmentantes e, dependendo da variedade, pode conter altos níveis de tanino.

Os taninos são substâncias polifenólicas encontradas no pericarpo dos grãos de sorgo (peso molecular de 500 a 3.000), que conferem aos grãos um sabor adstringente, tornando o sorgo com alto teor de tanino resistente ao ataque de pássaros, fungos causadores da podridão antes da colheita e insetos.

O principal problema do tanino, quando presente no sorgo, é a complexação com proteínas, que afeta a digestibilidade e modifica a palatabilidade (Magalhães et al., 2000). Acredita-se que a associação do tanino com proteína e a estabilidade deste complexo se devem, sobretudo, à formação de pontes de hidrogênio e a interações hidrofóbicas entre essas moléculas, observando-se que as proteínas diferem significamente quanto à sua afinidade pelos taninos.
No entanto, o emprego de grãos úmidos, principalmente de milho, na forma de silagem em rações para animais não ruminantes, especialmente suínos, tem sido uma alternativa para a produção de grãos na propriedade, apresentando várias vantagens em relação ao milho seco: ausência de taxas e impostos sobre o produto, de perdas econômicas com transporte, de frete e de desconto sobre a umidade; menor custo de armazenamento; antecipação do período de colheita; e menores perdas por ataques de roedores e insetos. Para suínos em fase de creche, Oliveira et al. (2004) concluíram ser possível a substituição total do milho seco por silagem de grãos úmidos de milho.

Para frangos de corte, os resultados obtidos com silagem de grãos úmidos de milho (Hunt et al., 1997; Martins et al., 2000; Carrijo et al., 2000) ainda são contraditórios.

Scapinello et al. (2001) concluíram, em estudo com coelhos em crescimento, que a silagem de grãos úmidos de milho é uma opção viável para substituição do milho seco nas rações.

O grão de sorgo, por sua vez, também tem sido utilizado como substituto ao milho, em forma de silagem, na alimentação animal. Garcia et al. (1996) concluíram que é viável a utilização de grãos úmidos de sorgo de baixo tanino em rações para frangos de corte.

Pesquisas têm indicado que o tanino presente em algumas variedades de sorgo pode trazer prejuízos no desempenho de não ruminantes (Alvarenga, 1979; Rostagno, 1986). Contudo, a incubação anaeróbica do sorgo com alta umidade tem reduzido o teor de tanino quimicamente detectável (Teeter et al., 1986), melhorando o desempenho animal (Mitaru et al., 1984a).

Considerando o significativo aumento da produção de sorgo nas propriedades agrícolas brasileiras e a escassez de informações sobre a utilização da silagem de grãos na alimentação animal, justifica-se o maior direcionamento de trabalhos para avaliação do desempenho de coelhos alimentados com esse produto.

Nesse contexto, os objetivos neste trabalho foram avaliar, em ensaio de digestibilidade e experimento de desempenho, o uso da silagem de grãos úmidos de sorgo de baixo ou de alto conteúdo de tanino, em substituição ao milho seco em rações para coelhos em crescimento.

\section{Material e Métodos}

Dois experimentos foram conduzidos no setor de cunicultura da Fazenda Experimental de Iguatemi, da Universidade Estadual de Maringá.

No ensaio de digestibilidade, foram utilizados 30 coelhos da raça Nova Zelândia Branco, (15 machos e 15 fêmeas), com 
idade inicial de 55 dias, distribuídos em um delineamento inteiramente casualizado, com três tratamentos e dez repetições. Os animais foram alojados individualmente em gaiolas para estudos de metabolismo, providas de bebedouros automáticos, comedouros semi-automáticos e bandejas e baldes de coleta (em separado) de fezes e urina, instaladas em galpão de alvenaria com pé direito de $3 \mathrm{~m}$ e cobertura de telha de barro.

O período experimental teve duração de 11 dias, sete para adaptação dos animais às instalações e às dietas e quatro para a coleta de fezes. Os tratamentos consistiram de uma ração-referência (Tabela 1) e de outras duas, nas quais as silagens de grãos úmidos de sorgo de baixo (DAS 741) ou de alto (BRS 700) conteúdo de tanino substituíram em $30 \%$ a ração-referência. Os grãos úmidos de sorgo foram triturados em moinho do tipo martelo, com peneira de $2 \mathrm{~mm}$ e foram devidamente compactados.

O silo utilizado para a silagem de sorgo de baixo teor de tanino foi de manilha de concreto, com capacidade para $1.000 \mathrm{~kg}$, enquanto, para o sorgo de alto teor de tanino, foram utilizados tambores plásticos de $200 \mathrm{~kg}$.

As rações experimentais foram peletizadas a seco, em temperaturas de 70 a $80^{\circ} \mathrm{C}$.

Durante todo o experimento, os animais foram alimentados, à vontade, uma vez ao dia e tiveram livre acesso à água.

As fezes foram coletadas diariamente, pela manhã, acondicionadas em congelador a $-10^{\circ} \mathrm{C}$ e, ao final do período de coleta, foram descongeladas e mantidas em estufa ventilada a $55^{\circ} \mathrm{C}$, por 72 horas, para pré-secagem. Posteriormente, foram expostas ao ar, para que houvesse equilíbrio com a temperatura e umidade ambiente. Foram, então, pesadas, moídas e homogeneizadas, retirando-se, em seguida, amostras do material seco para análises.

As análises químicas dos ingredientes, das rações e das fezes foram realizadas de acordo com os métodos descritos por Silva \& Queiroz (2002) e Mara (1992) e as análises dos teores de energia, em um calorímetro PARR, modelo 1281.

Foram determinados os teores de tanino dos grãos de sorgo secos, úmidos no momento da ensilagem, na silagem e depois do final do processo fermentativo, de acordo com o Método Azul da Prússia, descrito por Magalhães et al. (2000).

Os teores de amido dos alimentos e das fezes foram determinados de acordo com o método enzimático proposto por Poore et al. (1989), adaptado por Pereira \& Rossi (1995).

$\mathrm{O}$ pH da silagem de grão úmido de sorgo (SGUS) foi obtido pelo método utilizado por Phillip \& Fellner (1992) e a granulometria das silagens, pela metodologia descrita por Zanotto \& Bellaver(1996).
Tabela 1- Composições percentual e química da ração-referência (matéria natural)

Table 1 - Chemical and ingredient compositions of the basal diet (as fed basis)

\begin{tabular}{lc}
\hline $\begin{array}{l}\text { Ingrediente } \\
\text { Ingredient }\end{array}$ & $\%$ \\
\hline Milho, moído (Corn) & 19,31 \\
Farelo de soja (Soybean meal) & 12,80 \\
Farelo de trigo (Wheat meal) & 20,00 \\
Feno de alfafa (Alfalfa hay) & 20,00 \\
Feno de cynodon (Cynodon hay) & 22,50 \\
Sal comum (Salt) & 0,50 \\
Calcário (Limestone) & 0,52 \\
Fosfato bicálcico (Dicalcium phosphate) & 0,72 \\
Suplemento vit. + min ${ }^{1}$. (Vit. ${ }^{+}$min. supplement) & 0,50 \\
DL-metionina (DL-methionine) & 0,14 \\
Óleo vegetal (Vegetable oil) & 3,00 \\
Antioxidante (Antioxidant) & 0,01 \\
Total & 100,00
\end{tabular}

Composição calculada ${ }^{2}$

Calculated composition ${ }^{2}$

Matéria seca (\%) (Dry matter, \%)

89,10

Proteína bruta (\%) (Crude protein, \%)

16,00

$\mathrm{ED}(\mathrm{kcal} / \mathrm{kg})(D E, \mathrm{kcal} / \mathrm{kg})$

Fibra bruta (\%) (Crude fiber, \%)

Cálcio (\%) (Calcium, \%)

Fósforo (\%) (Phosphorus, \%)

2.400

Met.+Cis. (\%) (Met. + Cis, \%)

14,52

0,80

0,50

Lisina $(\%)$ (Lysine, \%)

0,60

0,80

1 Suplemento vitamínico-mineral, composição por kg do produto: Vit. A 300.000 UI; Vit. D, 50.000 UI; Vit. E, 4.000 mg; Vit. K3, $100 \mathrm{mg}$; Vit. B1 $200 \mathrm{mg}$; Vit. B2, $300 \mathrm{mg}$, Vit. B6, $100 \mathrm{mg}$; Vit. B12, $1.000 \mathrm{mcg}$; ác. nicotínico, $1.500 \mathrm{mg}$; ác. pantotênico, $1.000 \mathrm{mg}$; colina, $35.000 \mathrm{mg}$; ferro, $4.000 \mathrm{mg}$; cobre, $600 \mathrm{mg}$; cobalto, $100 \mathrm{mg}$; manganês, $4.300 \mathrm{mg}$; zinco, $6.000 \mathrm{mg}$; iodo, $32 \mathrm{mg}$; selênio, $8 \mathrm{mg}$; metionina, $60.000 \mathrm{mg}$; promotor de crescimento, $1.500 \mathrm{mg}$; coccidiostático, $12.500 \mathrm{mg}$; antioxidante, $10.000 \mathrm{mg}$

2 Com base nos valores de composição químicas das matérias-primas das rações (Rostagno et al,. 2000).

1 Vitamin-mineral premix (Nuvital) composition per kg: Vit. A, 300.000 UI; Vit. D, 50.000 UI; Vit. E, $4.000 \mathrm{mg}$ : Vit. K3, $100 \mathrm{mg}$; Vit. B1, $200 \mathrm{mg}$ :Vit. B2, $300 \mathrm{mg}$, Vit. B6, $100 \mathrm{mg}$ : Vit. B12, $1.000 \mathrm{mcg}$; nicotinic ac, $1.500 \mathrm{mg}$; panthotenic ac., $1.000 \mathrm{mg}$; choline, $35.000 \mathrm{mg}$; iron, $4.000 \mathrm{mg}$; copper, $600 \mathrm{mg}$; cobalt, $100 \mathrm{mg}$; manganese, $4.300 \mathrm{mg}$, znc, $6.000 \mathrm{mg}$; iodine $32 \mathrm{mg}$; selenium, $8 \mathrm{mg}$; methionine, $60.000 \mathrm{mg}$; growth promoter, $1.500 \mathrm{mg}$; coccidiostat $12.500 \mathrm{mg}$; Sinox, $10.000 \mathrm{mg}$

2 Based on the values of chemical composition of the dietary raw materials (Rostagno et al. 2000).

Foram feitas avaliações da estabilidade aeróbica das silagens, tomando-se as medidas de temperatura e, simultaneamente, a temperatura ambiente no momento e 1, 2, 3, $6,7,8,9$ e 10 horas após a abertura dos silos.

Para determinação dos teores de MS, MO, proteína, amido e energia digestíveis de cada alimento estudado, foi utilizada a fórmula de Matterson et al. (1965).

Os coeficientes de digestibilidade aparente da MS, $\mathrm{MO}, \mathrm{PB}$, do amido e da EB das duas variedades de sorgo ensiladas foram analisados de acordo com o modelo estatístico:

$$
\mathrm{Y}_{\mathrm{ij}}=\mu+\mathrm{T}_{\mathrm{i}}+\mathrm{e}_{\mathrm{ij}}
$$

em que: $Y_{i j}=$ coeficientes de digestibilidade aparente da MS, MO, PB, do amido e da EB de cada indivíduo j recebendo 
o sorgo $\mathrm{i} ; \mu=$ constante geral; $\mathrm{T}_{\mathrm{i}}=$ efeito da variedade de sorgo ensilada $i$, sendo $i=1 ; 2$ ( $1=$ silagem de grãos úmidos de sorgo de baixo tanino e 2 = silagem de grãos úmidos de sorgo de alto tanino); $\mathrm{e}_{\mathrm{ij}}=$ erro aleatório associado a cada observação $\mathrm{Y}_{\mathrm{ij}}$.

No experimento de desempenho, foram utilizados 84 coelhos da raça Nova Zelândia Branco (42 machos e 42 fêmeas), desmamados aos 35 dias de idade, com peso médio inicial de $850 \mathrm{~g}$, alojados em gaiolas de arame galvanizado, providas de bebedouro automático e comedouro semiautomático de chapa galvanizada, localizadas em galpão de alvenaria com cobertura de telha francesa, pé-direito de $3,0 \mathrm{~m}$, piso em alvenaria, paredes laterais de $50 \mathrm{~cm}$ em alvenaria e o restante em tela e cortina de plástico para controle da ventilação. A temperatura média registrada no período experimental foi de $20,3^{\circ} \mathrm{C}$, com máxima de $31^{\circ} \mathrm{C}$ e mínima de $9^{\circ} \mathrm{C}$.
Os animais foram distribuídos em um delineamento experimental inteiramente casualizado, com sete tratamentos, 12 repetições e um animal por unidade experimental.

Os tratamentos consistiram de uma ração-referência (Tabela 2) contendo milho seco e de outras seis, nas quais o milho seco foi substituído, com base nos valores energéticos, pela silagem de grãos úmidos de sorgo (SGUS) de baixo ou alto conteúdo de tanino em níveis de 33, 66 e $100 \%$, totalizando sete tratamentos.

As rações foram balanceadas para serem isoenergéticas, isocálcicas, isofosfóricas e isoaminoacídicas em metionina + cistina e lisina, de acordo com as recomendações para coelhos em crescimento (De Blas \& Mateos, 1998).

As rações fornecidas, as sobras e os animais foram pesados no início do experimento, aos 35 dias de idade e no final do experimento, aos 75 dias. $\mathrm{O}$ abate dos animais e a

Tabela 2 - Composições percentual e química das rações experimentais (matéria natural)

Table 2 - Chemical and percentual composition of experimental diets (as fed basis)

\begin{tabular}{|c|c|c|c|c|c|c|c|}
\hline \multirow[t]{3}{*}{$\begin{array}{l}\text { Ingrediente } \\
\text { Ingredient }\end{array}$} & \multirow[t]{3}{*}{$\begin{array}{c}\text { Testemunha } \\
\text { Control }\end{array}$} & \multicolumn{6}{|c|}{$\begin{array}{c}\text { Nível de substituição (\%) } \\
\text { Replacement level (\%) }\end{array}$} \\
\hline & & \multicolumn{3}{|c|}{$\begin{array}{c}\text { Silagem sorgo baixo tanino } \\
\text { Low tannin sorghum silage }\end{array}$} & \multicolumn{3}{|c|}{$\begin{array}{l}\text { Silagem sorgo alto tanino } \\
\text { High tannin sorghum silage }\end{array}$} \\
\hline & & 33 & 66 & 100 & 33 & 66 & 100 \\
\hline Milho (Corn) & 25,00 & 16,67 & 8,33 & - & 16,67 & 8,33 & - \\
\hline Silagem sorgo baixo tanino (Low tannin sorghum silage) & - & 7,86 & 15,72 & 23,58 & - & - & - \\
\hline Silagem sorgo alto tanino (High tannin sorghum silage) & - & - & - & - & 8,12 & 16,24 & 24,37 \\
\hline Farelo de soja (Soybean meal) & 10,40 & 10,40 & 10,40 & 10,40 & 10,40 & 10,40 & 10,40 \\
\hline Farelo de trigo (Wheat meal) & 20,00 & 20,63 & 21,29 & 21,92 & 20,31 & 20,59 & 20,85 \\
\hline Feno de alfafa (Alfalfa hay) & 20,00 & 20,00 & 20,00 & 20,00 & 20,00 & 20,00 & 20,00 \\
\hline Feno cynodon (Cynodon hay) & 20,00 & 20,00 & 20,00 & 20,00 & 20,00 & 20,00 & 20,00 \\
\hline Sal comum (Salt) & 0,50 & 0,50 & 0,50 & 0,50 & 0,50 & 0,50 & 0,50 \\
\hline Calcário (Limestone) & 0,54 & 0,53 & 0,52 & 0,51 & 0,54 & 0,54 & 0,54 \\
\hline Fosfato bicálcico (Dicalcium phosphate) & 0,45 & 0,46 & 0,46 & 0,47 & 0,45 & 0,45 & 0,45 \\
\hline Suplemento Vit. $+\operatorname{Min}^{2}($ Vit. + min. supplement $)$ & 0,50 & 0,50 & 0,50 & 0,50 & 0,50 & 0,50 & 0,50 \\
\hline $\mathrm{L}-\mathrm{Lis} \mathrm{HCl}(\mathrm{L}-L i s-H C L)$ & 0,09 & 0,09 & 0,08 & 0,08 & 0,09 & 0,09 & 0,09 \\
\hline DL-metionina (DL-methionine) & 0,11 & 0,11 & 0,11 & 0,11 & 0,11 & 0,11 & 0,11 \\
\hline Óleo vegetal (Vegetable oil) & 2,40 & 2,24 & 2,08 & 1,92 & 2,30 & 2,24 & 2,18 \\
\hline Antioxidante (Antioxidant) & 0,01 & 0,01 & 0,01 & 0,01 & 0,01 & 0,01 & 0,01 \\
\hline Total & 100 & 100 & 100 & 100 & 100 & 100 & 100 \\
\hline
\end{tabular}

Composição calculada ${ }^{1}$

Calculated composition ${ }^{1}$

\begin{tabular}{|c|c|c|c|c|c|c|c|}
\hline Matéria seca, (\%) (Dry matter, \%) & 88,18 & 88,20 & 88,18 & 88,20 & 88,20 & 88,00 & 88,00 \\
\hline Proteína bruta, (\%) (Crude protein, \%) & 16,25 & 16,35 & 16,46 & 16,56 & 16,24 & 16,23 & 16,22 \\
\hline $\mathrm{ED}(\mathrm{kcal} / \mathrm{kg})(D E, \mathrm{kcal} / \mathrm{kg})$ & 2.550 & 2.550 & 2.550 & 2.550 & 2.550 & 2.550 & 2.550 \\
\hline Fibra bruta (\%) (Crude fiber, \%) & 13,27 & 13,34 & 13,41 & 13,48 & 13,36 & 13,45 & 13,53 \\
\hline Cálcio, (\%) (Calcium, \%) & 0,80 & 0,80 & 0,80 & 0,80 & 0,80 & 0,80 & 0,80 \\
\hline Fósforo, (\%) (Phosphorus, \%) & 0,50 & 0,50 & 0,50 & 0,50 & 0,50 & 0,50 & 0,50 \\
\hline Met + Cis $(\%)($ Met + Cys, \%) & 0,60 & 0,60 & 0,60 & 0,60 & 0,60 & 0,60 & 0,60 \\
\hline Lisina (\%) (Lysine, \%) & 0,80 & 0,80 & 0,80 & 0,80 & 0,80 & 0,80 & 0,80 \\
\hline
\end{tabular}

${ }^{1}$ Com base nos valores de composição químicas das matérias-primas das rações (Rostagno et al,. 2000).

2 Suplemento vitamínico-mineral, composição por kg do produto: Vit. A, 300.000 UI; Vit. D, 50.000 UI; Vit. E, 4.000 mg; Vit. K3, 100 mg; Vit. B1, $200 \mathrm{mg}$; Vit. B2, 300 mg, Vit. B6, $100 \mathrm{mg}$; Vit. B12, $1.000 \mathrm{mcg}$; ác. nicotínico, 1.500 mg; ác. pantotênico, $1.000 \mathrm{mg} ; \mathrm{colina}, 35.000 \mathrm{mg}$; ferro, $4.000 \mathrm{mg}$ cobre, 600 mg; cobalto, 100 mg; manganês, 4.300 mg; zinco, 6.000 mg; iodo, 32 mg; selênio, 8 mg; metionina, 60.000 mg; promotor de crescimento, 1.500 mg; coccidiostático, $12.500 \mathrm{mg}$; antioxidante, $10.000 \mathrm{mg}$.

1 Based on the values of chemical composition of the dietary raw materials (Rostagno et al., 2000).

2 Vitamin-mineral premix (Nuvital) composition per kg: Vit. A, 300.000 Ul; Vit. D, 50.000 Ul; Vit. E, 4.000 mg; Vit. K3, 100 mg; Vit. B1, 200 mg; Vit. B2, 300 mg, Vit. B6, 100 mg; Vit. B12, $1.000 \mathrm{mcg}$; nicotinic ac, $1.500 \mathrm{mg}$; panthotenic ac., $1.000 \mathrm{mg}$; choline, $35.000 \mathrm{mg}$; iron, $4.000 \mathrm{mg}$; copper, $600 \mathrm{mg}$; cobalt, $100 \mathrm{mg}$; manganese, $4.300 \mathrm{mg}$, znc, $6.000 \mathrm{mg} ;$ iodine, $32 \mathrm{mg}$; selenium, $8 \mathrm{mg}$; methionine, $60.000 \mathrm{mg}$; growth promoter, $1.500 \mathrm{mg}$; coccidiostat, $12.500 \mathrm{mg}$; Sinox, $10.000 \mathrm{mg}$. 
avaliação das carcaças, no final do experimento, foram realizados conforme descrito por Scapinello (1993).

Para verificar a viabilidade econômica da substituição do milho seco pela silagem de grãos úmidos de sorgo nas rações, determinou-se inicialmente o custo da ração por ganho de peso vivo em quilograma $\left(\mathrm{Y}_{\mathrm{i}}\right)$, segundo Bellaver et al. (1985):

$$
\mathrm{Y}_{\mathrm{i}}=\frac{\mathrm{Q}_{\mathrm{i}} X \mathrm{P}_{\mathrm{i}}}{\mathrm{G}_{\mathrm{i}}}
$$

em que $Y_{i}=$ custo da ração por quilograma de peso vivo ganho no i-ésimo tratamento; $\mathrm{P}_{\mathrm{i}}=$ preço por quilograma da ração utilizada no i-ésimo tratamento; $\mathrm{Q}_{\mathrm{i}}=$ quantidade de ração consumida no i-ésimo tratamento; $\mathrm{G}_{\mathrm{i}}=$ ganho de peso do i-ésimo tratamento.

Em seguida, foram calculados o índice de eficiência econômica (IEE) e o índice de custo (IC), propostos por Gomes et al. (1991).

$$
\mathrm{IEE}=\frac{\text { Mcei }}{\mathrm{CTei}} \mathrm{x} 100 \quad \text { e } \quad \frac{\mathrm{IC}}{\mathrm{MCei}} \mathrm{CTei} \times 100
$$

em que $\mathrm{MCe}$ = menor custo da ração por quilograma ganho observado entre tratamentos; $\mathrm{Ctei}=$ custo do tratamento $\mathrm{i}$ considerado.

As observações foram analisadas de acordo com o modelo estatístico:

$$
\mathrm{Y}_{\mathrm{ijkl}}=\mu+\mathrm{F}_{\mathrm{i}}+\mathrm{N}_{\mathrm{j}}+\mathrm{FN}_{\mathrm{jj}}+\mathrm{S}_{\mathrm{k}}+\mathrm{b}_{1}\left(\mathrm{Pi}_{\mathrm{ijk}}-\mathrm{Pi}\right)+\mathrm{e}_{\mathrm{ijkl}},
$$

em que $\mathrm{Y}_{i j k l}=$ observação $l$ do sexo $k$, do nível de substituição $j$, referente ao efeito da variedade do sorgo $i ; \mu=$ constante geral; $\mathrm{F}_{i}=$ efeito da variedade de sorgo $i, \operatorname{com} i=1$; $2(1=$ silagem de grãos úmidos de sorgo de baixo teor de tanino e 2 = silagem de grãos úmidos de sorgo de alto tanino); $\mathrm{N}_{j}=$ efeito do nível de substituição $j ; \mathrm{FN}_{j j}=$ efeito da interação da efeito da variedade de sorgo $i$ com o nível de substituição $j ; \mathrm{S}_{k}=$ efeito do sexo $k$, com $k=1,2 ; \mathrm{b}_{1}=$ coeficiente de regressão linear da variável $\mathrm{Y}$ em função do peso inicial (Pi) e; $\mathrm{e}_{i j k l}=$ erro aleatório associado a cada observação $\mathrm{Y}_{i j k l}$.
Quando ocorreu interação significativa entre variedade de sorgo e nível de substituição, procedeu-se ao desdobramento da interação aninhando-se nível dentro de cada variedade de sorgo.

Foi realizada análise de variância e todos os tratamentos e graus de liberdade referentes a níveis de substituição do milho pelo sorgo de baixo ou alto conteúdo de tanino foram desdobrados em polinômios.

\section{Resultados e Discussão}

Comparando-se, na mesma base de matéria seca, a composição química das silagens de grãos de sorgo de baixo e alto conteúdo de tanino (Tabela 3) com os sorgos de baixo e alto conteúdo de tanino apresentados nas Tabelas da Embrapa (1991) e por Rostagno et al. (2000), observa-se que os teores de $\mathrm{MO}, \mathrm{PB}, \mathrm{EB}, \mathrm{Ca}$ e $\mathrm{P}$ foram bastante próximos. Pequenas diferenças na composição podem ser atribuídas, principalmente, aos diferentes cultivares utilizados.

Os valores de $\mathrm{pH}$ nas duas silagens de sorgo, variando de 4,20 e 4,65, podem ser considerados satisfatórios e encontram-se próximos daquele encontrado por Romero et al. (1996) em silagem de grãos de sorgo.

Os teores de tanino para o sorgo de baixo conteúdo de tanino variaram de 0,44 a $0,69 \%$ (Tabela 4 ). De acordo com Magalhães et al. (2000), percentuais abaixo de $0,70 \%$ no grão são promovidos por outros fenóis e não pelos taninos condensados e, portanto, não são prejudiciais aos animais. Entretanto, Brand et al. (1992), citado por Viljoen et al. (2000) afirmam que o conteúdo de tanino varia de 0,24 a $0,28 \%$ nas variedades de baixo conteúdo de tanino e de 0,94 a $1,72 \%$ naquelas de alto teor de tanino.

Neste estudo, os teores de tanino para o sorgo de alto conteúdo de tanino variaram entre $1,44 \%$ (sementes secas antes do plantio) e 1,14\% (silagem após o período fermentativo). Constata-se, portanto, que, durante o processo fermentativo da silagem, ocorreu redução de cerca de $20 \%$ nos teores de tanino.

Tabela 3 - Composição das silagens de sorgo de baixo e alto conteúdo de tanino (com base na matéria seca) ${ }^{1}$

\begin{tabular}{|c|c|c|c|c|c|c|c|c|c|c|}
\hline $\begin{array}{l}\text { Alimento } \\
\text { Food }\end{array}$ & $\begin{array}{l}\text { MS (\%) } \\
D M(\%)\end{array}$ & $\begin{array}{c}\text { MO }(\%) \\
O M(\%)\end{array}$ & $\begin{array}{c}\mathrm{EB}(\mathrm{kcal} / \mathrm{kg}) \\
G E(\mathrm{kcal} / \mathrm{kg})\end{array}$ & $\begin{array}{l}\text { PB }(\%) \\
C P(\%)\end{array}$ & $\begin{array}{c}\mathrm{AM}(\%) \\
S(\%)\end{array}$ & EE $(\%)$ & $\mathrm{Ca}(\%)$ & $\mathrm{P}(\%)$ & $\mathrm{pH}$ & $\begin{array}{l}\text { TP }(\mathrm{mm}) \\
P S(\mathrm{~mm})\end{array}$ \\
\hline $\begin{array}{l}\text { Silagem sorgo baixo tanino } \\
\text { Low tannin sorghum silage }\end{array}$ & 65,89 & 97,59 & 4533 & 10,37 & 68,66 & 3,17 & 0,046 & 0,218 & 4,20 & 678 \\
\hline $\begin{array}{l}\text { Silagem sorgo alto tanino } \\
\text { High tannin sorghum silage }\end{array}$ & 68,76 & 97,76 & 4521 & 9,20 & 65,21 & 2,65 & 0,023 & 0,287 & 4,65 & 571 \\
\hline
\end{tabular}

Table 3 - Dry matter (DM), organic matter (MO), gross energy (GE), crude protein (CP), starch (S), ether extract (EE), calcium (Ca) and phosphorus (P) composition, $\mathrm{pH}$ and particle size of low and high tannin silage (dry matter basis) ${ }^{1}$

\footnotetext{
${ }_{1}^{1}$ Análises realizadas no Laboratório de Nutrição Animal no Departamento de Zootecnia da UEM.
}

1 Analyses carried out in Animal Nutrition Laboratory of Animal Science Departament of UEM. 
Tabela 4 - Níveis de taninos/compostos fenólicos nos grãos secos, nos grãos úmidos e na silagem dos grãos de sorgo de baixo e alto conteúdo de tanino

Table 4 - $\quad$ Tannins/Phenolics levels in dry grains, high moisture grains and in grain silage of low and high tannin sorghum

\begin{tabular}{lccc}
\hline & $\begin{array}{c}\text { Grãos secos } \\
\text { Dry grains }\end{array}$ & $\begin{array}{c}\text { Grãos úmidos } \\
\text { High moisture grains }\end{array}$ & $\begin{array}{c}\text { Silagem } \\
\text { Silage }\end{array}$ \\
\hline $\begin{array}{l}\text { Sorgo de baixo tanino } \\
\text { Low tannin sorghum }\end{array}$ & 0,44 & 0,44 & 0,69 \\
$\begin{array}{l}\text { Sorgo de alto tanino } \\
\text { High tannin sorghum }\end{array}$ & 1,44 & 1,09 & 1,14 \\
\hline
\end{tabular}

Segundo Mitaru et al. (1984a), um tratamento utilizado para a detoxicação de grãos de sorgo, chamado reconstituição, envolve a adição de água ao grão, diminuindo o teor de MS para $70 \%$, e a subseqüente incubação anaeróbica a $32^{\circ} \mathrm{C}$, removendo até $100 \%$ do tanino quimicamente detectável.

Em pesquisa com grão de sorgo de alto conteúdo de tanino, esses autores constataram que a incubação anaeróbica (reconstituição) reduziu o conteúdo de taninos, com conseqüente melhora na eficiência alimentar de suínos.

Os coeficientes de digestibilidade dos principais nutrientes das silagens de grãos úmidos de sorgo de baixo e alto conteúdo de taninos encontram-se na Tabela 5 . Embora não se tenha obtido diferenças significativas entre os coeficientes de digestibilidade da MS, MO, PB e EB para ambos os tipos de silagem de grãos úmidos de sorgo, verificou-se que, numericamente, os coeficientes foram superiores para a silagem de grãos de baixo teor de tanino em 3,7\% para MS, em 3,5\% para MO, em 9,5\% para $\mathrm{PB}$ e em $3,1 \%$ para EB.

Os teores de tanino na silagem de grão de alto conteúdo de tanino sofreram pequena redução, ou seja, o processo de ensilagem não foi efetivo para reduzir eficientemente todo o tanino desses grãos (Tabela 4).

De acordo com Magalhães et al. (2000), o principal problema ocasionado pela presença do tanino no sorgo é a complexação com proteínas, que afeta a digestibilidade e modifica a palatabilidade. Acredita-se que a associação do tanino com a proteína e a estabilidade deste complexo se deve, sobretudo, à formação de pontes de hidrogênio e interações hidrofóbicas entre essas moléculas, de modo que as proteínas diferem significativamente quanto à sua afinidade pelos taninos.

A influência metabólica do tanino sobre a ação enzimática digestiva promove redução das disponibilidades dos nutrientes no grão de sorgo de baixo e alto teor de tanino. Halley et al. (1986) também notaram redução na digestibilidade da MS e EM em aves alimentadas com sorgo de alto tanino.
Tabela 5 - Coeficientes de digestibilidade da MS, MO, PB, AM e EB das silagens de sorgo de baixo (SSBT) e alto conteúdo (SSAT) de tanino

Table 5 - Digestibility coefficients of dry matter (DM), organic matter $(\mathrm{OM})$, crude protein (CP), starch (S) and gross energy (GE) of low (LTSS) and high tannin sorghum silage (HTSS) contents

\begin{tabular}{lrrrrr}
\hline & MS (\%) & MO (\%) & PB (\%) & AM (\%) & EB (\%) \\
& DM (\%) & OM (\%) & CP (\%) & \multicolumn{1}{c}{ S (\%) } & GE (\%) \\
\hline SSBT (LTSS) & 94,47 & 94,26 & 91,59 & 100,00 & 93,84 \\
SSAT(HTSS) & 91,06 & 91,09 & 83,65 & 100,00 & 91,04 \\
CV (\%) ${ }^{1}$ & 6,61 & 5,99 & 11,03 & 0,00 & 4,32 \\
\hline
\end{tabular}

${ }^{1}$ Coeficiente de variação.

1 Coefficient of variation.

Entretanto, Mitaru et al. (1984b) observaram que a reconstituição de grãos de sorgo de baixo e de alto teor de tanino com adição de $30 \%$ de água destilada e armazenamento a $25^{\circ} \mathrm{C}$ por 20 dias melhorou a digestibilidade da MS, da energia, da proteína e dos aminoácidos em dietas contendo sorgo de alto teor de tanino, mas não em dieta com sorgo de baixo teor de tanino.

Garcia \& Maier (1995) afirmam que na confecção da silagem os grãos de sorgo devem ser moídos para facilitar a compactação, condição necessária para garantir boa qualidade ao produto final. Além disso, a moagem ativa enzimas que promovem polimerização dos taninos em moléculas de peso molecular acima de 3.000 , amenizando os efeitos do tanino no sorgo.

A digestibilidade do amido, independentemente do tipo de silagem de grãos úmidos de sorgo, foi total, ou seja, o tanino presente nos grãos não reduziu a digestibilidade do amido.

Entretanto, Fialho \& Barbosa (1992) relataram a possibilidade de formação do complexo tanino-carboidrato, o que reduz a atividade das enzimas amilolíticas, ocasionando diminuição do metabolismo de carboidratos e, conseqüentemente, do aproveitamento energético do carboidrato.

O amido do sorgo, segundo Beth (2000), possui digestão mais lenta que o do milho, contudo, o processo de ensilagem aumenta a digestão do amido pela quebra da estrutura da proteína do grão e alteração da estrutura cristalina do amido.

De acordo com Sewell (2000), tratamentos com calor e armazenamento com alta umidade tornam o grão de sorgo nutricionalmente mais comparável ao milho.

As silagens de grãos úmidos de sorgo de baixo e alto conteúdo de taninos apresentaram teores de energia digestível de 4.285 e $4.116 \mathrm{kcal} / \mathrm{kg}$ MS, respectivamente (Tabela 6). O menor valor (4,2\%) observado para a silagem de grãos de sorgo de alto conteúdo de taninos pode também estar relacionado aos efeitos prejudiciais do tanino presente nos grãos. Segundo Rostagno (1986), o valor de EM 
está inversamente relacionado ao teor de tanino do cereal, o que torna impossível citar somente um valor energético para todas as variedades de sorgo.

Nunes et al. (2001) afirmam que o tanino condensado, além de afetar o valor nutricional dos alimentos de várias maneiras, formando complexos com proteínas, com íons metálicos divalentes, carboidratos e outras macromoléculas, também atua inibindo a atividade de várias enzimas digestivas e provocando erosões das células epiteliais do intestino, diminuindo a absorção dos nutrientes através da parede intestinal.

Os valores energéticos obtidos neste experimento para as silagens de grãos úmidos foram superiores aos encontrados por Furlan et al. (2002a), de $3.764 \mathrm{kcal} E D / \mathrm{kg}$ MS, para o sorgo, para coelhos em crescimento.

Se comparados aos do milho (Furlan et al. 2002,b), do triticale e do triguilho (Furlan et. al., 2002a), os valores energéticos das silagens de grãos de sorgo também foram superiores, indicando que esses alimentos são alternativas importantes para a formulação de rações para coelhos.

Observou-se (Tabela 7) que, logo na abertura do silo de sorgo de baixo conteúdo de tanino e até três horas após, houve aumento na temperatura da silagem, indicando atividade microbiológica neste período. Kung Jr. (2001) define a estabilidade aeróbia da silagem como o tempo observado para que a massa de forragem retirada do silo apresente elevação de $2^{\circ} \mathrm{C}$ na temperatura, em relação à temperatura ambiente. Assim, silagens estáveis apresentam baixa velocidade de deterioração na superfície frontal (painel), enquanto que a baixa estabilidade significa rápida deterioração.

Segundo Cai et al. (1999), silagens bem preservadas são freqüentemente consideradas mais propensas à deterioração aeróbia que as silagens mal fermentadas. A deterioração aeróbia resulta em perdas de MS e de importantes componentes nutricionais pela oxidação de ácido lático e de carboidratos solúveis. O acúmulo de produtos da degradação pode afetar a palatabilidade e, conseqüentemente, reduzir a ingestão (Holzer et al., 1999).

A estabilidade aeróbia da silagem do sorgo de alto conteúdo de tanino foi considerada satisfatória, pois não ocorreram alterações importantes na temperatura da silagem até 6 horas da abertura do silo.

Deve-se salientar que o silo utilizado para a silagem de sorgo de baixo conteúdo de tanino foi o de manilha de concreto com capacidade para $1.000 \mathrm{~kg}$, enquanto para o sorgo de alto conteúdo de tanino foram utilizados tambores plásticos de $200 \mathrm{~kg}$, que permitiram melhor vedação do material ensilado, garantindo melhor qualidade de fermentação.

No experimento de desempenho, a análise de variância não indicou diferenças $(\mathrm{P}>0,05)$ entre os tratamentos para as características de desempenho e carcaça, indicando a possibilidade de substituição total do milho por silagem de grãos úmidos de sorgo de baixo ou alto conteúdo de tanino (Tabela 8).

Contudo, excluindo a ração testemunha, a análise de regressão comprovou redução linear no ganho de peso $(\mathrm{P}<0,05)$ e piora linear na conversão alimentar $(\mathrm{P}<0,05)$ à medida que o milho foi substituído por silagem de grãos úmidos de sorgo de baixo conteúdo de tanino. A silagem de sorgo de baixo conteúdo de tanino apresentou atividade aeróbia nas primeiras horas de abertura do silo, o que pode ter comprometido, em parte, a qualidade da silagem, trazendo prejuízos ao desempenho.

Para o sorgo de alto conteúdo de tanino, não foram observadas diferenças $(\mathrm{P}>0,05)$ no desempenho e nas características de carcaça com a substituição gradativa do milho pela silagem.

De acordo com Teeter et al. (1986), a detoxicação de grãos de sorgo com alto teor de tanino melhorou a taxa de crescimento e a eficiência alimentar de suínos. Contudo, esses benefícios não foram evidenciados no mesmo processo aplicado aos grãos de sorgo contendo baixo tanino.

Apesar dos coeficientes de digestibilidade da MS, da $\mathrm{MO}$, da PB e da EB da silagem de grãos úmido de sorgo de alto conteúdo de tanino terem sido, numericamente, menores, estas diferenças não foram evidenciadas na análise do desempenho. Esses resultados podem ser explicados, em parte, pelo fato de as rações terem sido formuladas para serem isoenergéticas, o que amenizou os efeitos prejudiciais do tanino presente na silagem de grãos com alto conteúdo deste elemento.

Tabela 6 - Matéria seca digestível (MSD), matéria orgânica digestível (MOD), proteína digestível (PD), amido digestível (AMD) e energia digestível (ED) das silagens de baixo (SSBT) e alto conteúdo (SSAT) de tanino (base matéria seca)

Table 6 - Digestible dry matter (DDM), digestible organic matter (DOM), digestible protein (DP), digestible starch (DS) and digestible energy (DE) of foods (dry matter basis)

\begin{tabular}{lcccccc}
\hline $\begin{array}{l}\text { Nutriente digestível } \\
\text { Digestible nutrient }\end{array}$ & $\begin{array}{c}\text { IMSD (\%) } \\
D D M(\%)\end{array}$ & $\begin{array}{c}\text { MOD (\%) } \\
D O M(\%)\end{array}$ & $\begin{array}{c}\text { PD (\%) } \\
D P(\%)\end{array}$ & $\begin{array}{c}\text { AMD (\%) } \\
D S(\%)\end{array}$ & $\begin{array}{c}\operatorname{ED}(\mathrm{MS})(\mathrm{kcal} / \mathrm{kg}) \\
D E(D M)(\mathrm{kcal} / \mathrm{kg})\end{array}$ & $\begin{array}{c}\mathrm{ED}(\mathrm{MN})(\mathrm{kcal} / \mathrm{kg}) \\
D E(N M)(\mathrm{kcal} / \mathrm{kg})\end{array}$ \\
\hline SSBT (LTSS) & 62,25 & 91,99 & 9,50 & 66,22 & 4.285 & 2.803 \\
SSAT (HTSS) & 62,61 & 89,05 & 7,70 & 65,76 & 4.116 & 2.830 \\
\hline
\end{tabular}


Tabela 7 - Estabilidade aeróbia de silagens de grãos úmidos de sorgo medida pelo controle de temperatura Table 7 - Aerobic stability of high moisture sorghum silage mensure through temperature control

Horas após abertura dos silos Time after silo opening
Estabilidade aeróbia

Aeorobic stability

$\begin{array}{llllllllll}0 & 1 & 2 & 3 & 4 & 5 & 6 & 7 & 8\end{array}$

Silagem sorgo baixo tanino

Low tannin sorghum silage

Temperatura ambiente $\left({ }^{\circ} \mathrm{C}\right)$

Environment temperature

Temperatura da silagem $\left({ }^{\circ} \mathrm{C}\right)$

13,0

17,0

12,9

14,0

17,2

18,5

16,1

20

19,5

19,8

23,8

22,6

21,9

21,8

Silage temperature

Silagem sorgo alto tanino

High tannin sorghum silage

Temperatura ambiente $\left({ }^{\circ} \mathrm{C}\right)$

Environment temperature

Temperatura da silagem $\left({ }^{\circ} \mathrm{C}\right)$

Silage temperature

$\begin{array}{rrrrrrrrr}19,5 & 19,4 & 19,0 & 19,0 & 20,5 & 23,2 & 23,5 & 23,2 & 23,0 \\ 21,4 & 19,8 & 19,7 & 19,2 & 19,7 & 20,5 & 21,2 & 21,4 & 21,3\end{array}$

Tabela 8 - Ganho de peso médio diário (GPMD), consumo de ração médio diário (CRMD), conversão alimentar (CA), peso de carcaça (PC) e rendimento de carcaça ( $R C$ ) de coelhos em crescimento (35 a 75 dias de idade) alimentados com rações contendo níveis crescentes de silagem de grãos úmidos de sorgo de baixo e alto conteúdo de tanino

Table 8 - Daily average weight gain (DAWG), daily average feed intake (DAFI), feed:gain ratio (F:G), carcass weight (CW), carcass yield (CY) of growing rabbits (35- 75 days) fed diet with increasing levels of high moisture sorghum grain silage with high and low tannin content

\begin{tabular}{|c|c|c|c|c|c|c|c|c|c|c|c|}
\hline \multirow[b]{3}{*}{$\begin{array}{l}\text { Variável } \\
\text { Variable }\end{array}$} & \multicolumn{8}{|c|}{$\begin{array}{c}\text { Nível de substituição (\%) } \\
\text { Replacement level (\%) }\end{array}$} & \multirow[b]{3}{*}{ Média } & \multirow[b]{3}{*}{$\mathrm{EP}^{1}$} & \multirow[b]{3}{*}{$\mathrm{CV}^{2}$} \\
\hline & \multicolumn{4}{|c|}{$\begin{array}{l}\text { Silagem sorgo baixo tanino } \\
\text { Low tannin sorghum silage }\end{array}$} & \multicolumn{4}{|c|}{$\begin{array}{l}\text { Silagem sorgo alto tanino } \\
\text { High tannin sorghum silage }\end{array}$} & & & \\
\hline & 0 & 33 & 66 & 100 & Média & 33 & 66 & 100 & & & \\
\hline $\operatorname{GPMD}(\mathrm{g})^{3}(D A W G, \mathrm{~g})$ & 40,34 & 43,59 & 41,53 & 40,68 & 41,93 & 41,61 & 41,58 & 41,64 & 41,61 & 0,91 & 7,55 \\
\hline CRMD $(\mathrm{g})(D A F I, g)$ & 118,50 & 127,08 & 128,91 & 125,62 & 127,20 & 127,07 & 127,41 & 128,45 & 127,64 & 2,91 & 7,90 \\
\hline $\mathrm{CA}^{4}(F: G)$ & 2,95 & 2,91 & 3,10 & 3,10 & 3,04 & 3,05 & 3,07 & 3,10 & 3,07 & 0,05 & 5,53 \\
\hline $\mathrm{PC}(\mathrm{g})(C W, g)$ & 1177 & 1210 & 1190 & 1182 & 1194 & 1213 & 1194 & 1202 & 1203 & 21,90 & 6,32 \\
\hline $\mathrm{RC}(\%)(C Y, \%)$ & 49,36 & 48,74 & 49,05 & 49,40 & 49,06 & 49,94 & 49,20 & 49,48 & 49,53 & 0,39 & 2,74 \\
\hline
\end{tabular}

${ }^{1}$ Erro-padrão.

2 Coeficiente de variação.

${ }^{3}$ Efeito linear $(P<0,05)$, para silagem de sorgo de baixo tanino $(Y=44,64-0,0433 x)$

${ }^{4}$ Efeito linear $(P<0,05)$, para silagem de sorgo de baixo tanino $(Y=2,87+0,0027 x)$.

1 Standard error.

2 Coefficient of variation.

${ }^{3}$ Linear effect $(P<0.05)$, for low tannin sorghum silage $(Y=44.64-0.0433 x)$.

${ }^{4}$ Linear effect $(P<0.05)$, for low tannin sorghum silage $(Y=2.87+0.0027 x)$.

Tabela 9 - Custo da ração (CR), custo da ração por kg de peso vivo ganho de coelhos em crescimento (CRG), índice de eficiência econômica (IEE) e índice de custo

Table 9 - Cost of ration (CR), cost of ration per kilogram live weight gain of growing rabbits (GCR), economic efficiency index (EEl) and cost of index (CI)

\begin{tabular}{|c|c|c|c|c|c|c|c|c|c|c|}
\hline \multirow[b]{3}{*}{$\begin{array}{l}\text { Variável } \\
\text { Variable }\end{array}$} & \multicolumn{8}{|c|}{$\begin{array}{c}\text { Nível de substituição (\%) } \\
\text { Replacement level (\%) }\end{array}$} & \multirow[b]{3}{*}{ Média ${ }^{1}$} & \multirow[b]{3}{*}{$\mathrm{CV}^{2}$} \\
\hline & \multicolumn{4}{|c|}{$\begin{array}{l}\text { Silagem sorgo baixo tanino } \\
\text { Low tannin sorghum silage }\end{array}$} & \multicolumn{4}{|c|}{$\begin{array}{l}\text { Silagem sorgo alto tanino } \\
\text { High tannin sorghum silage }\end{array}$} & & \\
\hline & 0 & 33 & 66 & 100 & Média & 33 & 66 & 100 & & \\
\hline $\mathrm{CR}(C R)$ & 0,4187 & 0,4103 & 0,4009 & 0,3925 & 0,4012 & 0,4096 & 0,4010 & 0,3925 & 0,4010 & - \\
\hline $\mathrm{IEE}(E E I)$ & 96,59 & 100 & 95,84 & 98,29 & 98,04 & 95,47 & 97,07 & 98,19 & 96,91 & - \\
\hline $\mathrm{IC}(\mathrm{CI})$ & 103,53 & 100 & 104,34 & 101,74 & 102,03 & 104,74 & 103,02 & 101,85 & 103,20 & - \\
\hline
\end{tabular}

${ }^{1}$ Média para cada silagem, excluindo a ração-referência.

2 Coeficiente de variação.

${ }^{1}$ Mean for each silage, except of control diet.

2 Coefficient of variation. 
O custo da ração por quilograma de peso vivo ganho, o índice de eficiência econômica e o índice de custo não foram influenciados $(\mathrm{P}>0,05)$ pelos níveis de substituição do milho pelas silagens de grãos úmidos de baixo ou alto conteúdo de tanino (Tabela 9), evidenciando a possibilidade de substituição total do milho por silagens de grãos de sorgo nas rações.

O índice de eficiência econômica e de custo foram, numericamente, melhores nas rações com 33\% de substituição do milho pela silagem de grãos úmidos de sorgo de baixo conteúdo de tanino.

\section{Conclusões}

Nas condições em que o experimento foi realizado, conclui-se que as silagens de grãos úmidos de sorgo de baixo e alto conteúdo de tanino apresentam bom valor nutritivo e podem substituir totalmente o milho em rações para coelhos em crescimento.

\section{Literatura Citada}

ALVARENGA, J.C. Balanço da energia e da proteína de diferentes sorgos com suínos. Revista da Sociedade Brasileira de Zootecnia, n.8, p.152-170, 1979.

BELlAVER, C.; FIALHO, E.T.; PROTAS, J.F.S. et al. Radícula de malte na alimentação de suínos em crescimento e terminação. Pesquisa Agropecuária Brasileira, v.20, n.8, p.969-974, 1985.

BETH, M. Starch digestibility.[S.I.:Sn]. 2000. Disponível em: 27/07/2000. Acesso em: http://www.farme.com/assets/articles/ STARCHweb.htm

CAI, Y.; BENNO, Y.; OGAWA, M. et al. Effect of applying lactic acid bacterial isolated from forage crops on fermentation characteristics and aerobic deterioation of silage. Journal of Dairy Science, v.82, p.520-526. 1999.

CARRIJO, A.S.; MERLOTO, H.K.; AMARAL, A.N. Silagem de grãos de milho na alimentação de frangos de corte. Desempenho e rendimento de carcaça. In: CONFERÊNCIA APINCO DE CIÊNCIA E TECNOLOGIA AVÍCOLAS, 2000, Campinas. Anais... Campinas: Fundação Apinco de Ciência e Tecnologia Avícolas, 2000. p.50.

DE BLAS, C.; MATEOS, G.G. Feed formulation. In: DE BLAS, C.; WISEMAN, J. (Eds.) The nutrition of the rabbit. Cambridge: CABI Publishing, 1998. p.241-253.

EMPRESA BRASILEIRA DE PESQUISA AGROPECUÁRIA EMBRAPA. Tabela de composição química e valores energéticos de alimentos para suínos e aves. 3.ed. Concórdia: Embrapa Suínos e Aves, 1991. 97p.

FIALHO, E.T.; BARBOSA, H.C. Utilização de sorgo em rações para suínos e aves. Sete Lagoas: EMBRAPA - CNPMS, 1992. 19p. (Circular Técnica, 16).

FONTES, R. Conversão de sorgo para silagem chega a $60 \mathrm{mil}$ toneladas. [S.I.:Sn]. 2000. Acesso em: 23/05/2000. Disponível em: http://www.gazetamercantilce.com.br/jornal/3687.htm

FURLAN, A.C.; SCAPINELLO, C.; MURAKAMI, A.E. et al. Valor nutritivo de alguns alimentos para coelhos em crescimento de coelhos. In: REUNIÃO ANUAL DA SOCIEDADE BRASILEIRA DE ZOOTECNIA, 2002, Recife. Anais... Recife: Sociedade Brasileira de Zootecnia, 2002 (SBZ0616)

FURLAN, A.C.; MONTEIRO, R.T.; SCAPINELLO, C. et al. Digestibilidade do milho e do triticale extrusado ou não para coelhos em crescimento de coelhos. In: REUNIÃO ANUAL DA SOCIEDADE BRASILEIRA DE ZOOTECNIA, 2002, Recife, Anais... Recife: Sociedade Brasileira de Zootecnia, 2002 (SBZ0620).

GARCIA, D.C.; MAIER, J.C. Redução do teor de tanino no sorgo mediante moagem e armazenamento dos grãos e sua ação sobre o desempenho de pintos na fase inicial. Revista da Sociedade Brasileira de Zootecnia, v.42, n.1, p.70-77, 1995.

GARCIA, D.C.; MAIER, J.C.; FORLIN, F.J. Desempenho de pintos alimentados com grãos de sorgo úmidos, armazenados pelos sistemas convencional e hermético. Revista da Sociedade Brasileira de Zootecnia, v.25, n.2, p.261-269, 1996.

GOMES, M.F.M.; BARBOSA, H.P.; FIALHO, E.T. et al. Análise econômica da utilização do triguilho para suínos. (S.I.): EMBRAPA - Centro Nacional de Pesquisa de Suínos e Aves, 1991, p.1-2 (Comunicado Técnico, 179).

GONTIJO, V.P.M.; PEREIRA, J.A.A.; COSTA, P.M.A. et al. Substituição do milho pelo sorgo e sua suplementação com lisina e metionina em rações para suínos. Revista da Sociedade Brasileira de Zootecnia, v.5, n.1, p.83-95, 1976.

HALEY, J.T.; NELSON, T.S.; KIRBY, L.K., et al. The effect of tannin content of sorghum grain in poultry rations on drymatter digestion and energy utilization. Arkansas Farm Research, v.35, n.2, p.8, 1986.

HOLZER, M.; MAYRHUBER, H.; DANNER, L. Effect of Lactobacillus sp. On silaging and aerobic stability. In: INTERNACIONAL SILAGE CONFERENCE, 12., 1999, Uppsala. Anais... Uppsala: 1999. p.288-289.

HUNT, J.H.; LYONS, J.J.; VANDEPOPULIERE, J.M. Corn silage as a feedstuffs for broilers and turkeys. Journal of Applied Poultry Research, v.6, p.310-318, 1997.

KUNG, JR., L.; SHEPERD, A.C.; SMAGALA, A.M. et al. The effect of propionic acid-based preservatives on the fermentation and aerobic stability of corn silage and a total mixed ration. Journal of Dairy Science, v.81, p.1322-1330, 1998.

KUNG, Jr. Aditivos microbianos e químicos para silagem - Efeitos na fermentação e resposta animal. In: WORKSHOP SOBRE MILho PARA SIlagem, 2., 2001, Piracicaba. Anais... Piracicaba: Fundação de Estudos Agrários Luiz de Queiroz, 2001. p. $53-74$.

MAGAlhãeS, P.C.; RODRIGUES, W.A.; DURÃES, F.O.M. Tanino no grão de sorgo: bases fisiológicas e métodos de determinação. Sete Lagoas: EMBRAPA - CNPMS, 2000. 13p (Circular Técnica, 27).

MARTINS, C.L.; CRUZ, V.C.; PINHEIRO, D.F. Silagem de grãos úmidos de milho na alimentação de frangos de corte. Peso dos órgãos e morfometria intestinal. In: CONFERÊNCIA APINCO DE CIÊNCIA E TECNOLOGIA AVÍCOLAS, 2000, Campinas Anais... Campinas: Fundação Apinco de Ciência e Tecnologia Avícolas, 2000. p.49.

MATTERSON, L.D.; POTTER, L.M.; STUTZ, M.W. et al. The metabolically energy of feed ingredients for chickens. Storrs, Connecticut, The University of Connecticut, Agricultural Experiment Station, 1965. v.7, n.1, p.11-14 (Research Report)

MINISTÉRIO DA AGRICULTURA E REFORMA AGRÁRIA MARA. Métodos analíticos de controle de alimentos para uso animal. São Paulo, ANFAR: 1992. 208p.

MITARU, B.N.; REICHERT, R.D.; BLAIR, R. Nutritive value of reconstituted sorghum grains for weanling pigs. Journal of Animal Science, v. 58, n.5, p.1211-1215, 1984a.

MITARU, B.N.; REICHERT, R.D.; BLAIR, R. The binding of dietary protein by sorghum tannins in the digestive tract of pigs. The Journal of Nutrition, v.114, n.10, p.17871796, 1984b.

NUNES, R.V.; BUTERI, C.B.; NUNES, C.G.V. et al. Fatores antinutricionais dos ingredientes destinados à alimentação animal. In: SIMPÓSIO SOBRE INGREDIENTES NA ALIMENTAÇÃO ANIMAL, 2001, Campinas. Anais... Campinas: 2001. p.246-272. 
OLIVEIRA, R.P.; FURLAN, AC.; MOREIRA, I. et al. Valor nutritivo e desempenho de leitões alimentados com rações contendo silagem de grãos úmidos de milho. Revista Brasileira de Zootecnia, v.33, n.1, p.146-156, 2004.

PEREIRA, J.R.A.; ROSSI, J.R.P. Manual prático de avaliação nutricional dos alimentos. Piracicaba: Fundação de Estudos Agrários Luiz de Queiroz, 1995. 25p.

PHILLIP, L.E.; FELLNER, V. Effects of bacterial inoculation of high-moisture ear corn on its aerobic stability, digestion, and utilization for growth by beef steers. Journal of Animal Science, v.70, n.10, p.3178-3187, 1992.

ROMERO, L.A.; DIAZ, M.C.; BRUNO, O.A. et al. Silaje de grano húmedo de maiz y sorgo en la alimentación vacas lecheras. Santa Fé: Instituto Nacional de Tecnologia Agropecuária, 1996. 2p. (Informe Técnico, 110)

ROSTAGNO, H.S. Utilização do sorgo nas rações de aves e suínos. Informe Agropecuário, v.12, n.144, p.18-27, 1986.

ROSTAGNO, H.S.; ALBINO, L.F.T.; DONZELE, J.L. et al. Tabelas brasileiras para aves e suínos: composição de alimentos e exigências nutricionais. 1.ed. Viçosa, MG: Universidade Federal de Viçosa, 2000. 141p.

SCAPINELlO, C. Níveis de proteína bruta e de energia digestível e exigências de lisina e de metionina + cistina, para coelhos da raça Nova Zelândia Branco em crescimento. Viçosa, MG: Universidade Federal de Viçosa, 1993. 215p. Tese (Doutorado em Zootecnia) - Universidade Federal de Viçosa, 1993

SCAPINELLO, C.; FURLAN, A.C.; JOBIM, C. et al. Utilização de silagem de grão úmido de milho na alimentação de coelhos em crescimento. In: REUNIÃO ANUAL DA SOCIEDADE BRASILEIRA DE ZOOTECNIA, 38., 2001, Piracicaba. Anais... Piracicaba: Sociedade Brasileira de Zootecnia, 2001. p.14041405 .
SEWELL, H. B. Sorghum grain for beef cattle rations. [S.I.:Sn] 2000. Acesso em: 31/07/2000. Disponível em: http:// www.agricultural $/$ sorgo $\% 20$ cattle.htm.

SILVA, D.J.; QUEIROZ, AC. Análise de alimentos: métodos químicos e biológicos. Viçosa, MG: Universidade Federal de Viçosa, 2002. 235p.

TEETER, R. G.; SARANI, S.; SMITH, M. O. et al. Detoxification of high tannin sorghum grains. Poultry Science, v.65, n.1, p.67-71, 1986

VILJOEN, J. Sorghum as an animal feed. [S.I.:Sn]. 2000. Acesso em: 27/06/2000. Disponível em: http://www.agri24.com.

ZANOTTO, L.D.; BELLAVER, C. Método de determinação da granulometria de ingredientes para o uso em rações de suínos e aves. (S.I.): Centro Nacional de Pesquisa de Suínos e Aves/EMBRAPA, 1996. p.15 (Comunicado Técnico, 215). 